ACS Sustainable Chem. Eng. 4, 6090-6094 (2016)

DOI: $10.1021 /$ acssuschemeng. $6 \mathrm{~b} 01496$

\title{
Synthesis of Recyclable Tire Additives via Equilibrium Ring Opening Metathesis Polymerization
}

\author{
Robert Tuba, ${ }^{1,2}$ Janos Balogh, ${ }^{1}$ Antisar Hlil, ${ }^{1}$ Maciej Bartóg, ${ }^{1}$ \\ Mohammed Al-Hashimi, ${ }^{* 1}$ Hassan S. Bazzi ${ }^{* 1}$
}

${ }^{1}$ Department of Chemistry, Texas A\&M University at Qatar, P.O. Box 23874, Doha, Qatar. ${ }^{2}$ Institute of Materials and Environmental Chemistry, Research Centre for Natural Sciences, Hungarian Academy of Sciences Magyar tudósok körútja 2., 1519 Budapest, P.O. Box 286. *Email: tuba.robert@ttk.mta.hu, mohammed.al-hashimi@qatar.tamu.edu, bazzi@tamu.edu,

KEYWORDS: Ring opening metathesis polymerization (ROMP), silica composites, equilibrium polymerization, ruthenium catalysts, polypentenamer. 
ABSTRACT. Linear trans-polypentenamers are highly desired materials among the synthetic tire additives due to their comparable physical properties to natural rubber. Transpolypentenamer can be prepared by equilibrium ring-opening metathesis polymerization (ROMP) using well-defined ruthenium catalyst systems. This unique feature of the equilibrium polymerization reaction opens a way for the synthesis of durable, environmentally benign elastomers where polymers including synthetic tire additives can be synthesized and readily recycled using the same transition metal catalyst system.

The addition of silica fillers significantly improves the physical properties of the composite materials in comparison to the use of polymeric material. It is also known that the structural effects and the polymer-filler surface interaction are of prime importance. Herein, we report on the synthesis of silica filler compatible recyclable polypentenamer co-polymers via equilibrium ROMP of cyclopentene 1 and 4-(triethoxy)siloxy cyclopentene 11. It has been demonstrated that polypentenamer tire additive can be synthesized via equilibrium ROMP affording polymers with high yields $(>80 \%)$ at $0{ }^{\circ} \mathrm{C}$ and can be readily depolymerized at $40{ }^{\circ} \mathrm{C}$ and/or under diluted condition using the same metathesis catalyst systems. Furthermore, the polypentenamer can also be synthesized in neat at room temperature and at very low $\left(10^{5}\right)$ monomer/catalyst ratio. This methodology is based on the synthesis of polyolefins utilizing ruthenium based metathesis catalyst via equilibrium ROMP of cyclopentenes and their silylated derivatives. 


\section{INTRODUCTION}

Synthetic rubbers such as polypentenamers are highly relevant materials due to their exceptional physical and mechanical properties. ${ }^{1}$ Polypentenamer elastomers, especially their functionalized derivatives are of great industrial interest. In particular trans-polypentenamer is a remarkable polymer that has similar physical properties to natural rubber. ${ }^{2}$ Tires are usually composed from different rubber compounds, such as carbon black and/or silica, clay and different chemicals and minerals. They also contain steel and textile to improve the mechanical and physical properties. ${ }^{3}$ Typically $45-47 \%$ of a tire is composed of polymeric materials and $22 \%$ is made from carbon black and/or precipitated silica. The remaining $30 \%$ is steel and fabric, fillers and accelerators. ${ }^{4}$ The beneficial properties of silica and carbon black fillers as reinforcing agents in elastomers are well-known. ${ }^{5}$ It is well documented that the structural effects and the polymer-filler surface interaction are of significant importance. ${ }^{6}$ Moreover, it has also been reported that the increased number of grafted chains on the silica surface significantly increases the composite's elongation at break. ${ }^{7}$ Tire engineers around the world are working hard to develop new generation of high performance tire composites. Nerveless the tire recyclability has been and is still being an important challenge. One alternative for overcoming this environmental related issue is the use of trans-polypentenamer, which is readily obtained by equilibrium ring-opening polymerization of cyclopentene. ${ }^{8}$ Our previous and ongoing studies have demonstrated that ruthenium

metathesis catalysts (Figure 1) used for ring opening metathesis polymerization (ROMP) ${ }^{8 \mathrm{~d}-\mathrm{f}}$ of cyclopentene results in a cyclopentene-polypentenamer equilibrium mixture, whereby the monomer-polymer ratio can be fine-tuned by changing the reaction temperature. ${ }^{9}$ 


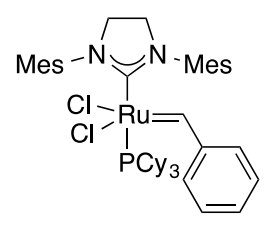

G2

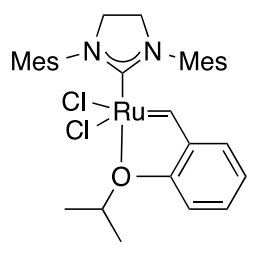

HG2

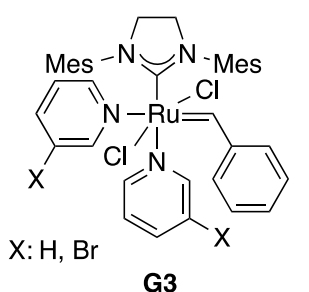

G3

Figure 1. Ru metathesis catalysts used for cyclopentene and functionalized cyclopentene ringopening metathesis polymerization.

Exploiting the temperature-dependence of the equilibrium polymerization provides high yield at $0{ }^{\circ} \mathrm{C}$ for polypentenamer $(>80 \%)$. However, increasing the reaction temperature $\left(>40{ }^{\circ} \mathrm{C}\right)$ will result in the polypentenamer/monomer equilibrium being shifted to the starting material. In theory we can postulate that polypentenamer tire additives may possibly be recyclable. Moreover, it is tentatively presumed that the polypentenamer starting material (cyclopentene, 1) and other components associated with the tires can be recovered.

Herein, we report our preliminary findings for recyclable and silica filler compatible polypentenamer tire additives. 


\section{RESULTS AND DISCUSSION}

We have recently reported the synthesis of polypentenamer by equilibrium ring-opening metathesis polymerization of cyclopentene using well-defined ruthenium catalysts G2, G3 and HG2 (Figure 1). The polymerization conditions including applied reaction temperature, type of catalyst and the loading has been studied in detail and optimized. A wide range of polypentenamers with molecular weights between $30-150 \mathrm{kDa}$ have been prepared during the study. ${ }^{9}$ The catalyst activity and loading was found to have a profound effect on the equilibrium time. However, as it was expected the overall monomer 1 conversion (i.e. equilibrium concentration) was influenced only by the applied reaction temperature. ${ }^{10}$ The thermodynamic parameters for the cyclopentene polymerization employing ruthenium-based complexes were calculated and found to be lower than those of achieved via tungsten catalyzed systems. ${ }^{11}$ Recently many transition metal complexes have been developed as cyclopentene polymerization catalyst. ${ }^{12}$ Nevertheless, ruthenium systems appear to be one of the most efficient catalysts for the equilibrium polymerization of wide range of functionalized cyclopentene species due to their higher stability and functional group tolerance

ROMP of cyclopentene at low catalyst loading in toluene. Following our previous studies and in order to widen the scope of such polymers, we decided to investigate the ROMP of cyclopentene at low catalyst loading. First, we studied the ruthenium complex $\mathbf{G 2}$ catalyzed cyclopentene polymerizations at room temperature $\left([\right.$ monomer $] /[$ catalyst $\left.]=10^{4}\right)$ in toluene. The molecular weight $\left(M_{W}\right)$ and molecular mass dispersities $(\nexists)$ of the polymer were determined as function of reaction time. It was found that within one hour the monomer-polymer equilibrium was achieved, while extended reaction time resulted in polymers with broader $D$ values and lower molecular weights (Table 1). The molecular weight of the polymer synthesized at room 
temperature $(\operatorname{tr}=1 \mathrm{~h})$ was determined by GPC to be $129 \mathrm{kDa}(\nexists: 1.64)$. This value is significantly higher than the reported values in the literature, where a higher catalyst loading was used (69.6 and $31.8 \mathrm{kDa}$ synthetized at 20 and $30{ }^{\circ} \mathrm{C}(Ð$ : 1.96 and 2.07 , respectively); $[$ monomer $] /[$ catalyst $]=10^{2.6} \approx 437 .{ }^{9}$ Lower molecular weights and higher $\oslash$ values were observed when the reaction time was extended from one to sixteen hours $\left(\mathrm{t}_{\mathrm{r}}=2 \mathrm{~h}-M_{W}: 106 \mathrm{kDa}\right.$, $\left.Ð: 1.77 ; \mathrm{t}_{\mathrm{r}}=4 \mathrm{~h}-M_{W}: 94.0, Ð: 1.82\right)$. This can be explained by the undesired cross-metathesis reaction of the formed, high molecular weight polymer due to the catalyst's relatively fast propagation and slow initiation rate, which is often observed for ROMP reactions using $\mathbf{G 2}$. $^{13}$ Comparison of polymers obtained by the ROMP of cyclopentene $\mathbf{1}$ and its siloxy functionalized derivative 11 showed afforded polymers with lower molecular weight and higher polydispersity $\left(\mathrm{t}_{\mathrm{r}}=2 \mathrm{~h}-M_{W}: 39.10 \mathrm{kDa}, Ð: 2.05\right)$ with reasonable isolated yield (Table 1).

Table 1. $M_{W}$ and molecular mass dispersity $(\bigoplus)$ values of polypentenamers derived from cyclopentene $\mathbf{1}$ isolated at different reaction times using catalyst $\mathbf{G} \mathbf{2}$.

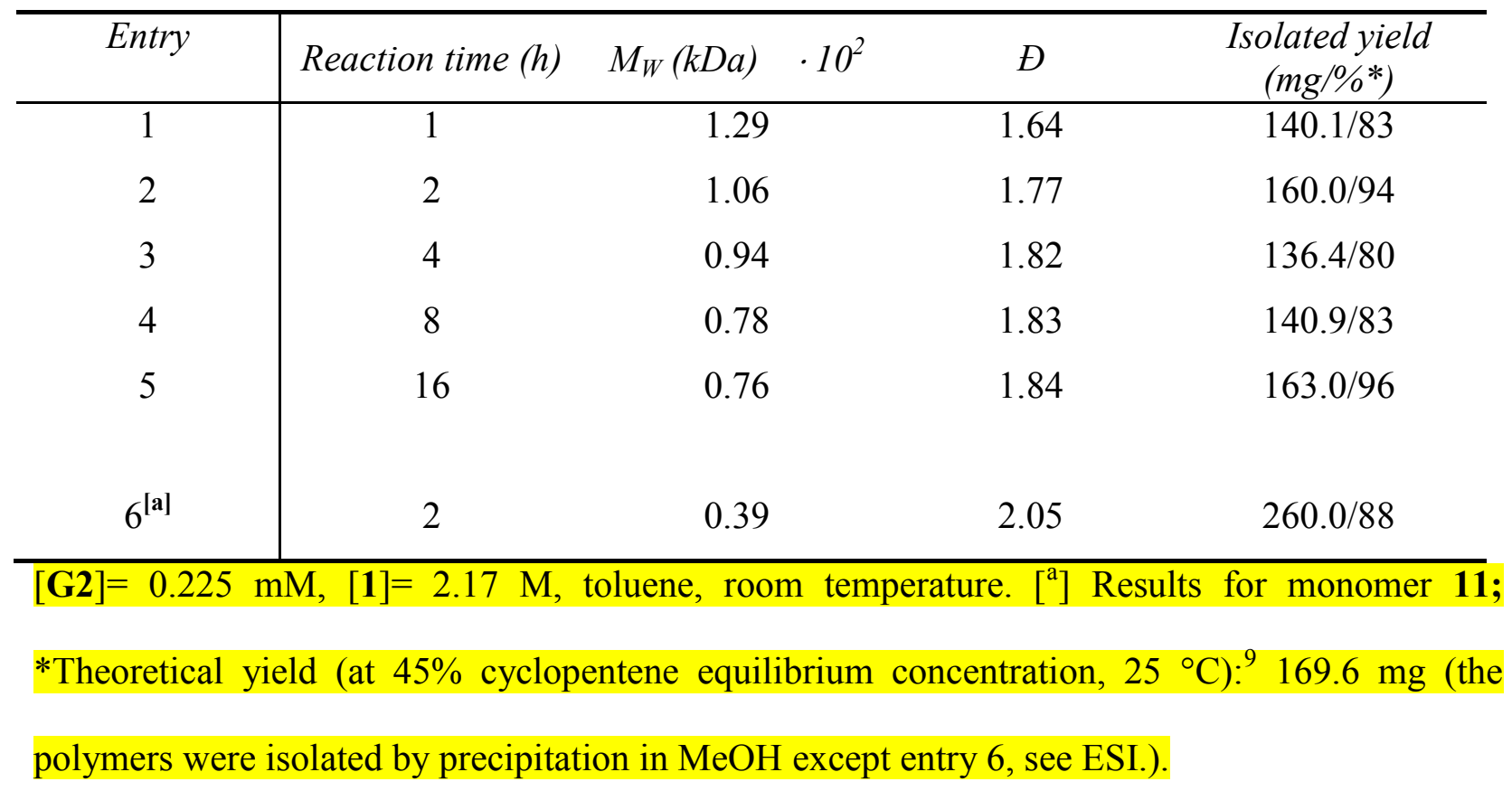


ROMP of cyclopentene at low catalyst loading in the absence of solvent. Herein, we studied the effect of solvent-free ROMP at low G2 catalyst loading. Preliminary results showed that at room temperature $\left(25^{\circ} \mathrm{C}\right)$ the reaction was very exothermic and the reaction mixture gelled within 20 minutes $\left([\right.$ Monomer $] /[$ Catalyst $\left.]=10^{4}\right)$. Actually, the reaction mixture warmed up and started to boil. Upon gelation gas bubbles were observed in the polypentenamer (Figure $\mathrm{S} 1$, PP-133). When the reaction was repeated at a slightly lower, thermostated reaction temperature $\left(20^{\circ} \mathrm{C}\right)$ (in order to avoid the mixture warming up that is caused by the exothermic reaction) longer gelation time was observed. After $15 \mathrm{~min}$ there was no gelation observed, the mixture solidified within $40 \mathrm{~min}$. Consequently, the reaction was also carried out at $0{ }^{\circ} \mathrm{C}$. As it was expected the polymerization took even longer ( $4.5 \mathrm{~h}$ until gelation). The polymerization was also tested at considerably low catalyst loading ([Monomer]/[Catalyst $\left.]=10^{5}\right)$. At room temperature the gelation was observed after 1h (Figure S1, PP-134). The polymerization was repeated using more active ruthenium complexes G3 and HG2 at $0{ }^{\circ} \mathrm{C}$ employing the same catalyst loading. However, to our surprise the reaction did not go to completion, even upon prolonged reaction time (3 days), no solidification was observed. This can only be explained by the very slow catalyst initiation rate at $0{ }^{\circ} \mathrm{C}$ and thus the very low active species concentration in the reaction mixture.

Synthesis of siloxy functionalized polypentenamers - Theoretical calculations. One possibility for enhancing and having a better affinity to the silica fillers is the introduction of siloxy functionalities onto the polymer backbone. It has tentatively been proposed that siloxy functionalized polypentenamer will result in a better silica/polypentenamer composite homogeneity. Therefore, preliminary theoretical calculations using density functional theory 
(DFT) have been performed to predict the ring strain energies and bond orders of siloxy functionalized cyclopentene derivatives as potential co-polymerization agents (Figure 2 and 3).
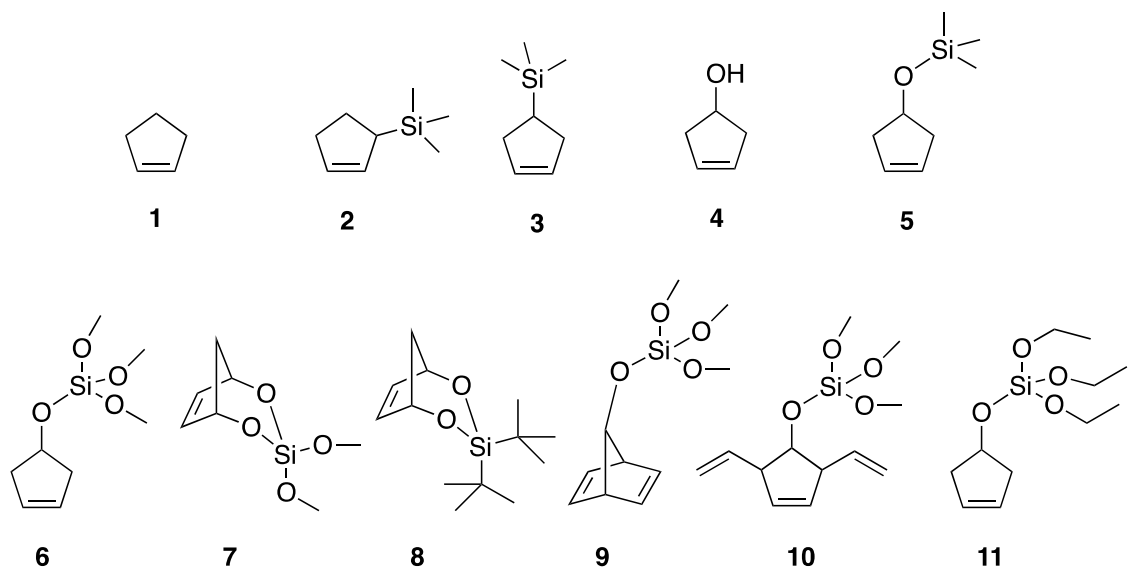

Figure 2. Cyclopentene and its functionalized derivatives used for ring strain energy calculations

The ring strain energy of a series of substituted cyclopenetene species have been calculated with DFT studies performed using RB3LYP method at 6-31G (D) basis set using SPARTAN '14 version 1.1.9 software (Figure 3, Table S1). ${ }^{14}$ 


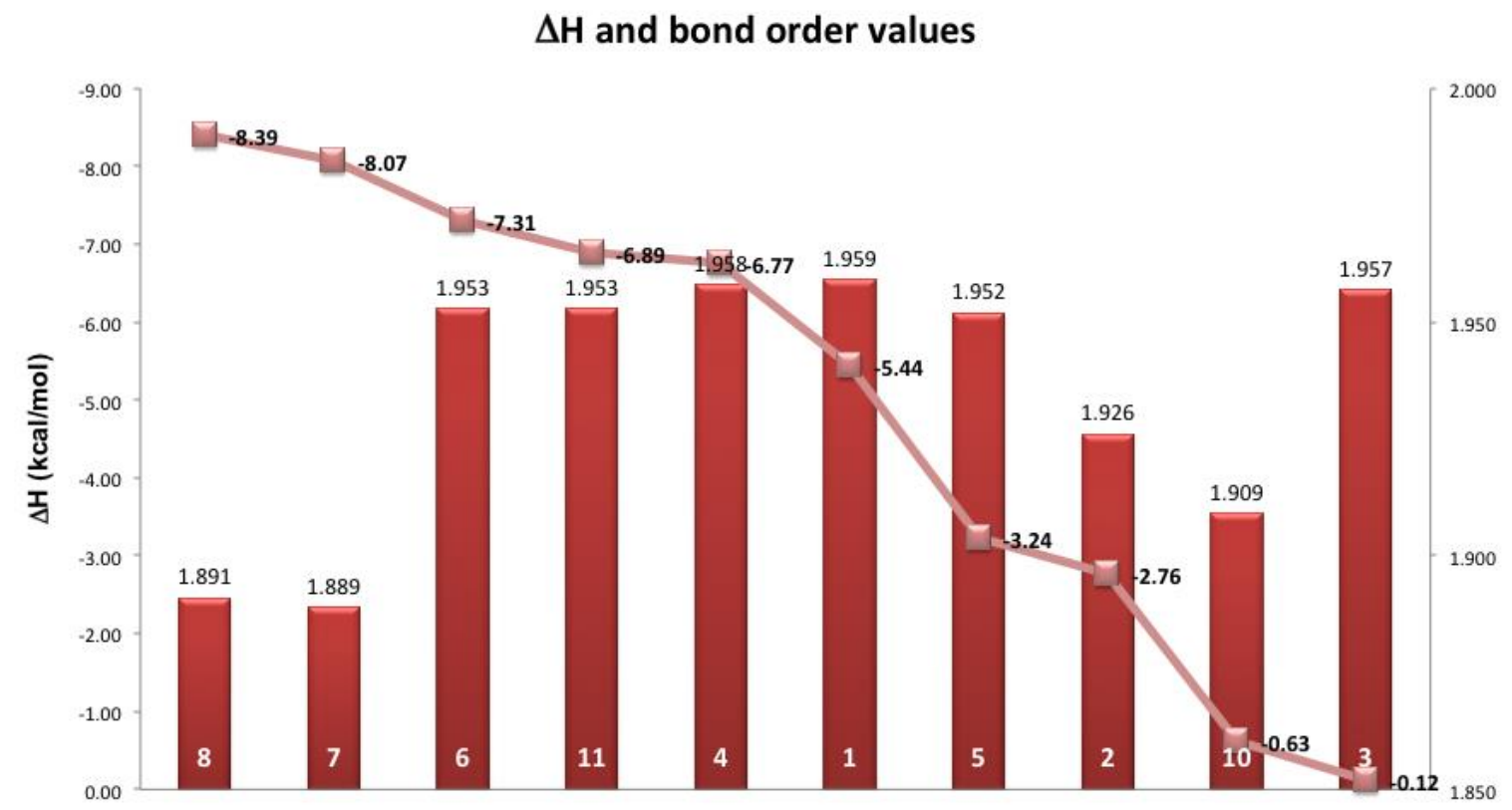

Figure 3. Ring strain energies (pink) and bond orders (red) calculated for $\mathbf{1}-\mathbf{1 1}$ monomer $(\mathbf{9}=$ $27.36 \mathrm{kcal} / \mathrm{mol})$

According to the DFT calculations, monomers 5, 6, 7 and 11 have mediocre ring strain energy (5: $-3.24 \mathrm{kcal} / \mathrm{mol} ; 6$ : $-7.31 \mathrm{kcal} / \mathrm{mol} ; 7:-8.07 \mathrm{kcal} / \mathrm{mol} ; 11:-6.89 \mathrm{kcal} / \mathrm{mol}$ ), while the bond order is $1.952 ; 1.953,1.889$ and 1.953 respectively (Table S1 and Figure 3). Thus, the equilibrium polymerization of these compounds was expected to be feasible. As can be seen from figure 3 monomers 6 and $\mathbf{1 1}$ have similar ring strain energies, as one might expect due to the small difference in chain length (monomer $\mathbf{6}$ having a methoxy group in comparison to monomer $\mathbf{1 1}$ having an ethoxy group). The ring strain energy calculated for monomer $\mathbf{8}$ is the highest among the above depicted cyclopentene species $(-8.39 \mathrm{kcal} / \mathrm{mol})$. This is in accordance with the reported data by Scherman et al. explaining why compound $\mathbf{8}$ can be readily polymerized by ROMP. ${ }^{15}$ Theoretically the ROMP of 9 may take place in two steps forming a branched polypentenamer. However, according to the theoretical calculations the second ROMP step of monomer 9, is most 
probably not feasible due to its relatively low strain energy of the formed cyclopentene species 10.

ROMP of (cyclopent-3-en-1-yloxy)trimethylsilane (5) and cyclopent-3-en-1-yl triethyl silicate (11) polypentenamers. Siloxy functionalized cyclopentenes were synthesized according to standard literature procedures with modifications (see supporting information). The ROMP reactions were carried out in toluene or toluene- $d_{8}$ solution at $0{ }^{\circ} \mathrm{C}$ using $0.2-0.7 \mathrm{~mol} \% \mathbf{G 2}$ or HG2 catalyst loading.

Referring to our theoretical calculation data due to the relatively low ring strain energy of $\mathbf{5}$ higher monomer equilibrium concentration or low activity was expected for the ROMP. As the green HG2 solution was added to the toluene solution of 5 the color of the mixture gradually turned to orange. The color change may have indicated the formation of an active catalyst species yet no formation of the polymer could be detected by ${ }^{1} \mathrm{H}$ NMR spectroscopy. The reaction was then repeated in neat. Following the addition of $\mathbf{5}$ to the catalyst there was no immediate gelation observed. However, the color of the mixture gradually turned from green to orange within $15 \mathrm{~min}$. The mixture became viscose after $30 \mathrm{~min}$ and solidified after $60 \mathrm{~min}$. After $3.5 \mathrm{~h}$ reaction time the solid polymer was dissolved in $\mathrm{CD}_{2} \mathrm{Cl}_{2}$ and analyzed by ${ }^{1} \mathrm{H} \mathrm{NMR}$ spectroscopy. The ${ }^{1} \mathrm{H}$ NMR spectrum showed a significant upshift of $-\mathrm{CH}=$ proton peaks. The magnitude of the chemical shifts and the shape (broad) of the peaks indicated the formation of 5poly (Figure S9). The polymer was isolated by precipitation using $\mathrm{MeOH}$. Following the purification procedure a colorless, waxy, dense polymer was isolated in $51.2 \%$ yield. Due to the relatively low strain energy of monomer $5(-3.24 \mathrm{kcal} / \mathrm{mol})$ in comparison to cyclopentene $(\mathbf{1}$; - 
$5.44 \mathrm{kcal} / \mathrm{mol}$ ) higher monomer concentration and most probably lower temperature is needed to achieve higher monomer conversions (i.e. lower monomer equilibrium concentration).
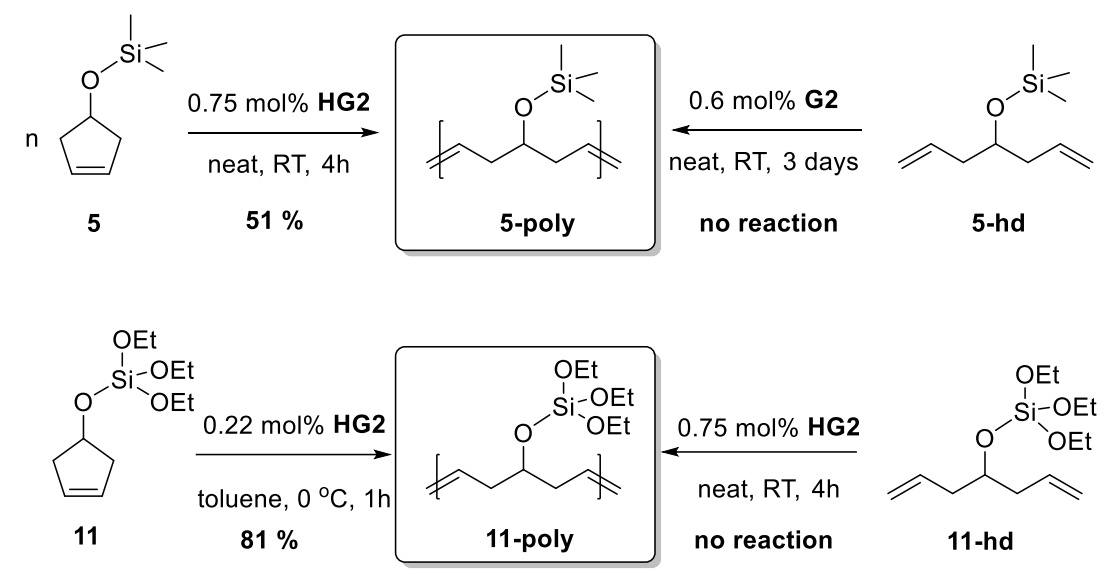

Scheme 1. Polymerization test of 5, 11 and 5-hd, 11-hd

Acyclic diene metathesis (ADMET) polymerization of 5-hd was also investigated at similar reaction condition using catalyst G2 (Scheme 1). It was found that the polymerization is not feasible either in solution or in neat. The mixture did not form a gel and no ethylene formation was observed even at prolonged reaction times (3 days).

In general, trialkoxy silane functionalized cyclopentenes have relatively higher ring strain energies $(6:-7.31 \mathrm{kcal} / \mathrm{mol}$ or cyclopent-3-en-1-yl triethyl silicate, 11: $-6.89 \mathrm{kcal} / \mathrm{mol})$ than the (cyclopent-3-en-1-yloxy)trimethylsilane (5: $-3.24 \mathrm{kcal} / \mathrm{mol})$. It was expected that the monomers should show lower monomer equilibrium concentration in comparison to the non-functionalized cyclopentene and therefore, result in a higher activity in the ruthenium catalyzed ROMP reactions. The polymerization of monomer 11 (2.1M in toluene), afforded the desired polymer with reasonable isolated yield (81\%). Interestingly, the ADMET of 11-hd did not afford the expected polymer either. Based on our recent thermodynamic and theoretical investigations it 
can be easily concluded that there is a correlation between the observed ring strain energies and monomer equilibrium concentration (i.e. conversion). ${ }^{9,14 a}$ The introduction of different functionalities on the cyclopentene ring has a significant impact on the ring strain and thus the equilibrium monomer concentration in ROMP reactions. The higher the ring strain the lower the monomer equilibrium concentration that was observed. For example introducing the $\mathrm{OSi}\left(\mathrm{CH}_{3}\right)_{3}$ group 5 results in lower ring-strain energy $(-3.24 \mathrm{kcal} / \mathrm{mol})$, which as a result the reaction could only be completed in neat. On the other hand introduction of hydroxyl $(\mathrm{OH})$ functionality $4^{14 a}$ or siloxyOSi $\left(\mathrm{OC}_{2} \mathrm{H}_{5}\right)_{3} 11$ groups significantly increase the ring-strain energies (-6.77 and -6.89 $\mathrm{kcal} / \mathrm{mol})$ and thus the reactivity. Moreover, high ( $>80 \%)$ conversion could be achieved even at 2.1 $\mathrm{M}$ toluene solution at lower temperature rang $0-10^{\circ} \mathrm{C}$.

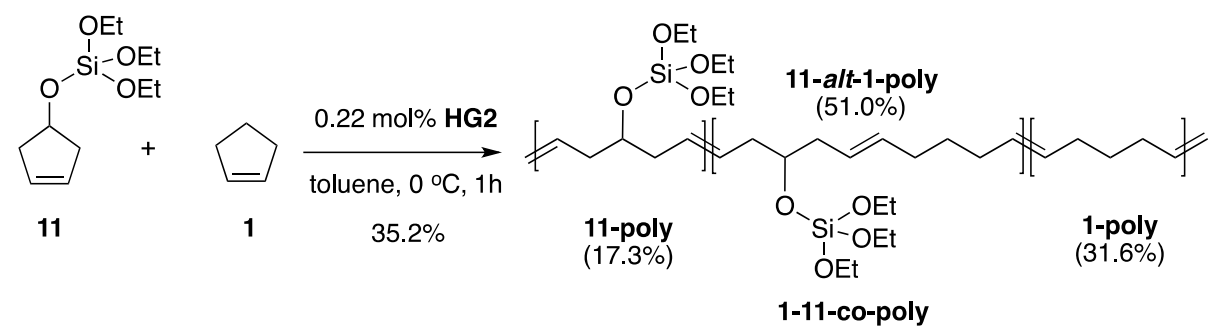

Scheme 2. Random co-polymerization of $\mathbf{1 1}$ and $\mathbf{1}$ in toluene.

Our recent studies have shown that the equilibrium co-polymerization of $\mathbf{1}$ and $\mathbf{4}$ resulted in a polymer having randomly distributed dyads. In general, it means that the co-polymer formed contains approximately $50 \%$ alternating polymer, $25 \% 1$ and $25 \% 4$ homo-polymer dyads. ${ }^{14 a}$

The random co-polymerization of $\mathbf{1}$ with $\mathbf{1 1}$ has also been investigated under identical molecular ratios. It was found that the co-polymerization product contains alternating 1-alt-11-poly (51.1\%), 1-poly (31.6\%) and 11-poly diads (17.3\%), which is comparable to the composition of polymers obtained during the co-polymerization of monomers 1 and $4 .^{14 a}$

Depolymerization of 1-poly, 11-poly and 1-11-co-poly polypentenamers. According to the thermodynamic investigations depolymerization can be enhanced either by slightly 
increasing the temperature (up to $50^{\circ} \mathrm{C}$ ) or by diluting the polymer solution. For example it was found that at higher dilutions ( $5 \mathrm{w} / \mathrm{v} \%$ polymer concentration) at room temperature the isolated polypentenamer can be fully depolymerized using the G2 complex within 4 min (Figure S15). Repeating the depolymerisation reaction of 11-poly and 1-11-co-poly resulted in the full monomer recovery based on in-situ ${ }^{1} \mathrm{H}$ NMR investigations (Figure S16-S17). If the depolymerization needs to be performed at higher polymer concentration then the equilibrium can be fully shifted to the depolymerization direction with increasing the temperature up to 50 ${ }^{\circ} \mathrm{C}$. If we consider that the boiling point of 1 is $44{ }^{\circ} \mathrm{C}$, then we can easily recognize that the polypentenamers can be fully depolymerized even at high concentrations and higher temperature $\left(50^{\circ} \mathrm{C}\right)$ and monomer 1 can easily be distilled off from the reaction mixture.

\section{CONCLUSION}

Earlier work using poorly defined catalysts demonstrated that polymers prepared from cyclopentene resulted in elastomers for tire applications that were more durable than the material used at the time. Manufacturing auto tires that would have a longer life and from starting materials that can be recycled will eliminate major disposal issues. Polypentenamers and their functionalized derivatives have great industrial interest, as these materials possess exceptional physical and mechanical properties. These materials will have a wide industrial and commercial application in areas including packaging, medicinal aid, petrochemical and tire productions.

We have reported that polypentenamer can be synthesized using very low $\left(10^{5}\right)$ monomercatalyst loading at $20{ }^{\circ} \mathrm{C}$ reaction temperature within a reasonable reaction time (3h) using welldefined ruthenium metathesis catalysts. In particular, one can postulate that $10 \mathrm{~kg}$ polypentenamer can be produced using only $1 \mathrm{~g}$ of the $\mathbf{G} \mathbf{2}$ catalyst. The recyclability of polypentenamer has been demonstrated using the same ruthenium metathesis catalyst systems at 
diluted condition or slightly elevated reaction temperature. The introduction of the siloxy functionalities will result in silica filler compatible polypentenamers. Theoretical calculations have also been carried out to illustrate that siloxy functionalized polypentenamers can be formed via equilibrium polymerization. This will result in a convenient method to recycle and achieve full monomer recovery. Additional studies are ongoing to explore additional types and new recyclable polymers that are based on high performing tire additives, which will be reported in due course.

\section{ASSOCIATED CONTENT}

The Supporting Information is available free of charge on the ACS Publications website at DOI:

\section{AUTHOR INFORMATION}

\section{Corresponding Authors}

*Dr. Robert Tuba. Tel: +36-20-980-4527. E-mail: tuba.robert@ttk.mta.hu.

*Dr. Mohammed Al-Hashimi. Tel: +974-4423-0185. E-mail: mohammed.al-

hashimi@qatar.tamu.edu

*Prof. Hassan S. Bazzi. Tel: +974-4423-0029. E-mail: hassan.bazzi@qatar.tamu.edu.

\section{Author Contributions}

The manuscript was written through contributions of all authors. All authors have given approval to the final version of the manuscript.

\section{Notes}


The authors declare no competing financial interest.

\section{ACKNOWLEDGMENT}

The authors gratefully acknowledge support of this work from the Qatar National Research Fund project number: NPRP X-095-1-024. The authors thank Prof. Robert H. Grubbs for his helpful consultations on the project. R. T. thanks the Hungarian Academy of Sciences and National Research, Development and Innovation Office (NKFIH) for financial support under Grant Nos. OTKA NN 117986. 


\section{REFERENCES}

[1] Tucker, H.; Minchak, R. J.; Macey, J. H. Polym. Eng. Sci., 1975, 15, 360.

[2] (a) K. Sanui, W. J. MacKnight and R. W. Lenz, Macromolecules, 1974, 7, 101. (b) J. K. Gillham and J. A. Benci, J. Appl. Polym. Sci., 1974, 18, 3775. (c) A. J. Amass, Br. Polym. J., 1972, 4, 327.

[3] French, T., Tyre Technology; Taylor \& Francis, the University of Michigan, 1989.

[4] Mark, J.; Erman, T.; Eirich, B. Editors., Science and Technology of Rubber; Academic Press: San Diego, 1994.

[5] (a) Donnet, J. B.; Voet A., Carbon Black Physics, Chemistry and Elastomer Reinforcement; Marcel Dekker, New York, 1976.; (b) Leblanc, J. L. Prog. Polym. Sci. 2002, 27, 627. (c) Boonstra, B. B.; Cochrane, H.; Dannenberg, E. M. Rubber Chem. Tech. 1976, 48, 558 . (d) Voet, A.; Morawski, J. C.; Donnet, J. B.; Rubber Chem. Tech. 1977, 50, 342. (e) Kelly, A. A Concise Encyclopedia of Composite Materials, New York, 1994.

[6] (a) Bronstein, L. M.; Karlinsey, J. R.; Zwanziger, J. W. Chem. Mater. 2001, 13, 3678.

(b) Hecht, A.-M.; Horkay, F.; Geissler, E. Phys. Rev. 2001, 64, 041402-1-6.

[7] Botti, A.; Pyckhout-Hintzen, W.; Richter, D.; Straube, E. Phys. A. 2002, 304, 230.

[8] (a) Natta, G.; Dall'Asta, G.; Mazzanti, G. Angew. Chem., 1964, 76, 765. (b) Kranz, D.; Beck, M. Angew. Makromol. Chem., 1972, 27, 29. (c) Lebedev, B. V.; Rabinovich, I. B.; Lityagov, Y. V. Doklady Akademii Nauk SSSR, 1977, 237, 877. (d) Scholl, M.; Lee, C. W.; Grubbs, R. H. Org. Lett. 1999, 1, 953-956. (e) Kingsbury, J. S.; Harrity, J. P.; Bonitatebus, P. J.; Hoveyda, A. H. J. Am. Chem. Soc. 1999, 121, 791-799. (f) M. S. Sanford, J. A. Love, R. H. Grubbs, Organometallics 2001, 20, 5314-5318 
[9] R. Tuba, R. H. Grubbs Polym. Chem., 2013, 4, 395.

[10] Ofstead, E. A.; Calderon, N. Makromol. Chem., 1972, 154, 21.

[11] Calderon, N.; Hinrichs, R. L. Chem. Technol., 1974, 627.

[12] (a) Jan, D.; Delaude, L.; Simal, F.; Demonceau, A.; Noels, A. F. J. Organomet. Chem., 2000, 606, 55. (b) Stüer, W.; Wolf, J.; Werner, H.; Schwab, P.; Schulz, M. Angew. Chem., Int. Ed., 1998, 37, 3421. (c) Myers, S. B.; Register, R. A. Polymer, 2008, 49, 877. (d) Bielawski, C. W.; Grubbs, R. H. Angew. Chem., Int. Ed., 2000, 39, 2903. (e) Coca, S.; Dimonie, M.; Dragutan, V.; Ion, R.; Popescu, L.; Teodorescu, M.; Moise, F.; Vasilescu, A. J. Mol. Catal., 1994, 90, 101. (f) Schrock, R. R.; Yap, K. B.; Yang, D. C.; Sitzmann, H.; Sita, L. R.; Bazan, G. C. Macromolecules, 1989, 22, 3191.

[13] Black, G.; Maher, D.; Risse, W. "Living Ring-Opening Olefin Metathesis Polymerization", in Handbook of Metathesis, R. H. Grubbs, Ed.;Vol. 3, Wiley/VCH, Weinheim, 2003, pp. 2-71.

[14] (a) Tuba, R.; Al-Hashimi, M.; Bazzi, H. S.; Grubbs, R. H. Macromolecules, 2014, 47, 8190. (b) Al-Hashimi, M; Tuba, R.; Bazzi, H. S.; Grubbs, R. H. ChemCatChem, 2016, 8, 228.

[15] Scherman, O.; Kim, H.; Grubbs, R. Macromolecules, 2002, 35, 5366. 